References

1 Dawkins, R. (1976) The Selfish Gene, Oxford University Press

2 Haig, D. (1996) Gestational drive and the greenbearded placenta. Proc. Natl. Acad. Sci. U. S. A 93, 6547-6551

3 Keller, L. and Ross, K.G. (1998) Selfish genes: a green beard in the red fire ant. Nature 394, 573-775

4 Temple-Smith, P.D. (1987) Possums and opossums. In Studies in Evolution (Archer, M. ed.), pp. 273-277, Surrey Beatty

5 Moore, H.D.M. (1996) Gamete biology of the new world marsupial, the grey short-tailed possum, Monodelphis domestica. Reprod. Fertil. Dev. $8,605-615$

\section{Marsupial sperm pairing: a case of 'sticky' green beards?}

\section{Response from Keller}

Sperm are often cartooned as selfish entities competing to fertilize the ovum; however, there are notable exceptions. In American marsupials, for example, sperm have to pair and cooperate to reach the site of fertilization. Sperm pairing has been described in the Virginian opossum Didelphis virginiana [1] and Moore and Moore [2] now propose that sperm pairing might have evolved by green-bearded selection.

To determine which selective forces are involved in the evolution of cooperation requires an understanding of the costs and benefits for the parties involved. For sperm pairing, the cost of cooperation is high because unpairing almost invariably disables one member of the pair. However, the benefits of cooperation are even higher because single sperm have virtually no chance of reaching the site of fertilization. Under such conditions, cooperation should always be favoured by individual selection (at the sperm level) provided that each sperm in a pair has an equal probability of being disabled. In fact, cooperation should always be favoured if the surviving sperm from a pair has at least twice the probability of fertilizing an egg compared with a non-cooperative sperm.

The situation is quite different if sperm in a pair differ in their probability of surviving. In this case, cooperation could evolve by individual selection only if each sperm in a pair has a greater probability of fertilizing an egg than it would by not cooperating. Differential survival between sperm in a pair also sets the stage for kin selection to operate if there are differences in relatedness among sperm. This would be the case if females mate with several males. With multiple mating, sperm will benefit from cooperating when Hamilton's rule [3] is fulfilled (which depends on the relative probability of sperm in a pair surviving, the benefits of pairing in terms of reaching the site of fertilization, and the difference in relatedness between paired sperm and sperm competing for fertilization).

So what about green-bearded selection? First, green-bearded selection requires (by definition) cooperation to be restricted to only those sperm carrying the green beard gene. Second, a green beard gene will spread only if sperm carrying it have a greater individual fitness than those lacking it (which is true whenever the surviving sperm from a pair has at least twice the probability of fertilizing an egg compared with a non-cooperative sperm). There are no data on whether these two conditions were fulfilled when sperm pairing first evolved.

The relative roles of individual, kin, and green-bearded selection will vary depending on female mating behaviour and whether sperm in a pair vary in their probability of being disabled during unpairing. For example, if the sperm have no 'information' on whether they will be disabled, the conditions favourable for cooperation are the same under both individual and greenbearded selection. (This is because there is no intragenomic conflict about whether to cooperate.) Thus, whether cooperation evolved by individual or green-bearded selection is merely semantic and the important issue relates to the proximate mechanisms underlying cooperation (e.g. whether a single gene is indeed involved, as assumed by green-bearded selection). However, under other conditions, such as multiple mating by females and survival difference between sperm in a pair, the conditions inducive to cooperation will differ depending on which party controls cooperation (the diploid male, the whole haploid genome of sperm, or a single gene in the sperm - as postulated by green-bearded selection). In short, Moore and Moore's suggestion is very interesting, but more information on the system is needed to determine whether green-bearded selection has indeed been an important selective force in the evolution of cooperative sperm.

\section{Laurent Keller}

Institute of Ecology, BB, University of Lausanne, 1015 Lausanne, Switzerland. e-mail: Laurent.Keller@ie-zea.unil.ch

\section{References}

1 Seleenka, E. (1887) Studien über Entwickelungsgeschichte. 4. Das Opossum, C.W. Kriedels

2 Moore, T. and Moore, H.D. (2002) Marsupial sperm pairing: a case of 'sticky' green beards? Trends Ecol. Evol. 17, 112-113

3 Hamilton, W.D. (1964) The genetical evolution of social behavior. I. J. Theor. Biol. 7, 1-16

\section{The species richness-productivity controversy}

The role of productivity in controlling biodiversity has been a central but contentious issue within ecology [1] Recent discussions about the relevance and interpretation of biodiversity experiments in grassland ecosystems have led to attempts to reconcile apparently contradictory experimental results with patterns observed in vegetation surveys [2]. However, as witnessed at two recent conferences* (the main topic of which was the functional significance of biodiversity) the controversy continues.

In his introductory talk at the Basel conference, Phil Grime explained results from observational studies by reference to the so-called 'hump-backed' model [3]. When results from experimental studies simulating random species extinctions [4] are superimposed on an idealized graph, they deviate from the hump-backed line, seemingly creating an inconsistency between observational and experimental studies (Fig. 1a). However, as most scatter-plots (e.g. Fig. 1b) and reviews of observational data show [1,5], the area below the hump-backed line is often filled with data points. The line might be better viewed as the upper boundary of an envelope of points rather than a line of fitted average values. Therefore, the trajectories followed by experimental species extinctions do not cross 'forbidden territory' in the productivity-diversity plane. Interestingly, negative experimental trajectories have only been found in cases where species extinctions were caused by a factor that simultaneously increased site fertility [6].

In a $3 \mathrm{D}$ graph, the hump-backed line could be envisaged above a diagonal line

* The 31st Annual Meeting of the Ecological Society of Germany, Austria and Switzerland in Basel and the 44th Congress of the International Association of Vegetation Science in Freising/Munich. 